\title{
COVID-19: A Perpetuating Challenge to Health Care Personnel
}

\author{
Aradhya Abrol ${ }^{1}$, Surbhi Abrol ${ }^{1}$, Savita Mahajan ${ }^{3 *}$, \\ Ram Kishan Abrol ${ }^{2}$ and Gurpreet Banga ${ }^{3}$ \\ ${ }^{1}$ Faculty of Medicine, Boston University, United States \\ ${ }^{2}$ Department of Surgery, ${ }^{3}$ Dept. of microbiology, Dr Rajendra Prasad Govt Medical College, \\ Kangra, Himachal Pradesh, India \\ *Corresponding author
}

\section{A B S T R A C T}

\begin{tabular}{|l|}
\hline Ke y w o r d s \\
COVID-19, \\
Health Care \\
Personnel
\end{tabular}

An ongoing outbreak of a new virus of a novel Coronavirus (nCoV) is a spill over event, with its epicentre in Wuhan, People of Republic of China has emerged as global health emergency. The outbreak began in December 2019 and now has been reported from about 180 countries. The emergence of SARS-CoV-2 has once again exposed the weaknesses of the global health systems preparedness, and ability to respond to an infectious threat. The present review highlights the updates of novel SARS- CoV-2 and also identifies the need to strengthen the health system and global health security.

\section{Introduction}

Coronavirus pandemic is a major threat to humanity. The world is facing another zoonotic infection caused by a novel strain of coronavirus (1). This new virus was provisionally named '2019-n CoV' by the world health organization (WHO), but now called (from $11^{\text {th }}$ Feb 2020) as 'severe acute respiratory syndrome coronavirus (SARSCoV-2) (2). This virus is a cause of coronavirus disease 2019 (Covid-19) and is contagious among humans (3). The virus is thought to have originated in animals $(4,5)$. This virus came to lime light following a spate of cases of pneumonia with no obvious reasons in December, 2019 from Wuhan City of China's Hubei province (6). The virus has now outspread globally and has become a problem of global concern. Human to human transmission of the virus has been confirmed (3).

Since the reports of the onset of infection leading to chaos and confusion from Wuhan city of China, the virus has rapidly spread to other parts of the world and has become perpetuating challenge to global medicine. On $11^{\text {th }}$ March, 2020, WHO officially declared it as a Pandemic. This infection has been 
reported from 180 countries and the number of morbidity and mortality is rising daily (1).

According to Reuters news dated $9^{\text {th }}$ June 2020, more than 7.14 million people have been infected with Novel Corona virus globally and 406,929 have died. In India, according to ministry of health and family welfare on $10^{\text {th }}$ June 2020 , total number of confirmed cases are 133632 whereas 135205 have been recovered and 7745 deaths have been reported. (7)

This infection has affected almost all continents except Antarctica and number of morbidity and mortality rising daily. But in China, now the reported cases are less as compared to the other parts of the world. Most unfortunate part of this is that there is no definite treatment and management for this problem and is still a distant dream.

According to the health officials, all the deaths may not have occurred only due to Corona virus infection, but may be due to comorbid conditions like asthma, diabetes, cardiac disease, cancer or immunocompromised patients etc. morbidity and mortality of health personals has also been reported throughout the world.

India faced a huge public crisis during this recent pandemic with tremendous pressure and resources constrain on the health care system.(8)

SARS-CoV-2 is a positive strand RNA virus (Fig I) belonging to the family of single stranded RNA viruses known as corona viridae and order - Nidovirus. It was believed to be a common type of virus which infects mammals, birds and reptiles but no previous report of human infection. However, Middle east Respiratory-syndrome first reported in Saudi Arabia in September 2012 and severe acute respiratory syndrome (SARS) identified in southern China in 2003 with case fatality rate as $35 \%$ and $10 \%$ respectively (9).

Unfortunately, the current situation looks grave, because Coronavirus is outspreading very swiftly among humans. Species emerging into an acute disease (10). Human Corona virus includes alpha-coronaviruses (229E and NL 63) beta-Coronaviruses (OC43 and HKU1) and middle east respiratory syndrome related coronavirus (MERS-CoV) etc (1).

\section{Transmission}

The cause of viral infection to human is not clear yet. There are reports of its origin in a seafood market with vats and other live animals in Wuhan and spread from these animals to human. Also, claims of the crossspecies dissemination between snake and humans are available in literature. However, no definite rate of animals in the channelling of this virus to humans is established $(11,12)$. Human to human transmission of the virus has been confirmed. Corona viruses are primarily spread through close contact in particular through respiratory droplets from cough and sneezes within range of about 6 feet $(13,14)$. Viral RNA has also been found in stool samples from infected patients $(13,14,15)$. WHO stated on 1 February 2020 that "transmission from Asymptomatic cases is likely not a major driver of transmission at this time but now it has been confirmed that transmission through asymptomatic carrier can occur"?.

The ICMR (Indian Council of Medical Research) - National institute of virology (ICMR-NIV) has carried out extensive data collection from bats, which may provide critical insight for the on-going spill over event. However, it remains difficult to say whether this virus will become entrenched with endemic seasonal or annual epidemics 
(like pandemic H1N1, influenza) $(17,18)$ or it would extinguish like SARS. The knowledge based around developing robust signals which can predict the emergency of viruses of this group or their mutants is still developing. The gap in the current evidence have no alternative except to prepare for combatting epidemic spill overs in the years ahead.

\section{Case definition}

According the WHO's interim guidance documents (19) the case definitions being used currently are

SARI - An acute respiratory infection with a history of fever or measure temperature $>38$ and cough onset within 10 days and requiring hospitalization.

Surveillance case definitions for SARS-CoV$2-$

A person with SARI with no other aetiologies with one of the following:

1. History of travel in last 14 days; and

2. Patient is an HCW who has been caring for patients with SARI of unknown aetiology.

Patient with acute respiratory illness and at least one of the following:

1. Close contact with a confirmed or probable case of SARS-CoV-2 in the 14 days before illness onset; (20)

2. Worked or attended health care facility in the 14 days before onset of symptom where patients with hospital-associated SARS-CoV infections were reported.

A sensitive and specific definition for community-based surveillance remains elusive. The indicators for referral and their outcome impact are yet to be ascertain symptomatically.

\section{Clinical manifestations}

Individual of all age groups are vulnerable to SARS-CoV-2. The aged and those with underlying chronic disease are highly susceptible to become acute cases (16).

The clinical features mainly involve the respiratory tract, the common presenting symptoms include fever (99\%), dry cough (60\%), fatigue (70\%), myalgia (44\%) and dyspnoea $(21,22)$. Less common symptoms are headache, dizziness, diarrhoea, nausea and vomiting (23). Symptoms such as pharyngeal pain, dyspnoea, dizziness, abdominal pain and anorexia are more likely to be present in patients with severe illness. In addition, patients who are elderly, have co-morbidities including hypertension, diabetes, cardiovascular disease and cerebrovascular disease are more likely to have adverse outcome. In severe cases the Corona virus can cause pneumonia, kidney failure, acute respiratory distress syndrome, septic shock, coagulation dysfunction and death (24).

\section{Laboratory diagnosis}

Diagnosis is suspected in patients with signs and symptoms of pneumonia or patients who satisfy clinical case definition and are epidemiologically linked to a history of travel from affected location or who have had contact with confirmed case of SARS-CoV-2 (25). Sample collection from both upper and lower respiratory tract are accepted nasal swab, oropharyngeal swab, sputum, bronchoalveolar lavage, endotracheal aspirate or wash and tissue biopsy are preferred samples and stool sample in case of diarrhoea. All the procedures from sample collection to packaging should be done taking stringent contact precautions, using PPE with eye protection, three layered surgical masks (N95 mask should be restricted to sample collection and in-patient care), disposable gown, gloves 
and shoe covers. This should be preferably be performed in a negative pressure isolation room. The collected sample should be referred to the designated laboratories assigned by the ICMR to test for novel Corona virus using Real time PCR.

A diagnostic test Real-time PCR has been developed and countries are quarantining and testing the suspected case by using test. The WHO recommends that RT-PCR must be done in BSL-2 laboratories (26). Routine confirmation of case of Covid-19 is based on detection of unique sequences of virus RNA by NAAT such as reverse RT-PCR with confirmation by nucleic acid sequencing when necessary.

The viral genes targeted so far, include, the N, E, S and RdRP genes. Heat treatment of RNA extraction is not recommended (27). Whole handling specimens of SARS-CoV-2, one must ensure neither the sample nor the HCW is contaminated. Charile Berlin, from Germany, was the first to develop the assay and standardize the protocol for real time PCR (28).

\section{Prevention}

As there is no specific treatment for Covid19 , complete isolation of confirmed cases is advised by the experts (1). SARS-CoV-2 spreads via respiratory droplets and physical contact. It is essential to practice precautionary measures to prevent transmission. Standard precautions consist of hand hygiene.

Use of personal protective equipment (PPE). Hand hygiene should be done with alcoholbased hand rubs containing 60-80\% ethanol. PPE consists of N-95 mask, face shield, goggles, gowns, gloves and shoe covers (29). Particulate i.e. NIOSH-certified N-95, EV standard FFP2 or equivalent should be used by HCWs involved in aerosol generating procedures in healthcare settings the COVID positive patients should be placed in a negative pressure isolation room.

\section{Quarantine}

On the present scenario when there is unavailability of drug and vaccine. The aim of WHO is to help the international community prevention and respond to acute public health care risk. The WHO has created a range of info-graphs to demonstrate how infected cases can protect themselves and others from catching the infection (27).

Importance of travel history is an imperative step to determine a patient rise of SARSCoV-2 (30). Quarantining the patient with a history of travel to infected locations or contact with an infected individual will help in preventing the spread of infection. By avoiding mass gathering, regular use of hand washing or hand sanitizers, also maintaining a distance of at least one meter from people who are coughing or sneezing will also help to reduce the infection (27). Anyone with flu should contact the health department for timely diagnosis and management.

\section{Treatment}

There is no specific drug for Covid-19. Treatment is mostly supportive based on the organ system affected. Published evidence for preliminary therapeutic experiences indicated that patients requiring hospitalization were managed with broad spectrum antibacterial, antibiotics and antiviral drugs.

The treatment course may require management of respiratory failure with noninvasive ventilation. 
Fig.1

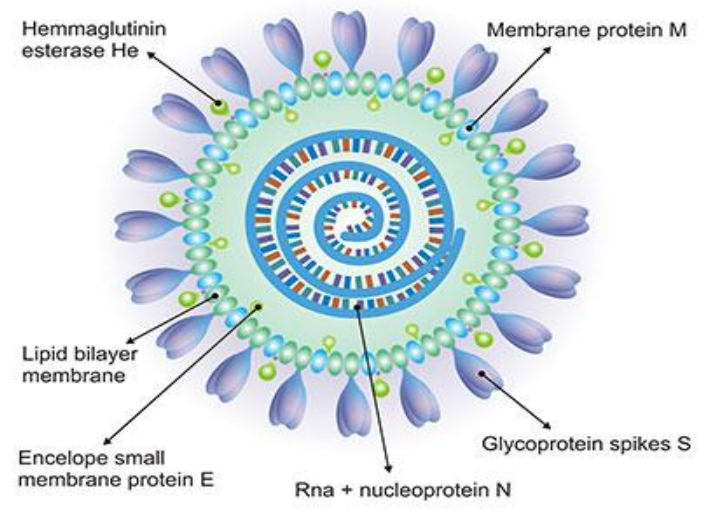

\section{Vaccine}

The WHO R\&D blueprint and it's working group conveyed an informal consultation on prioritization of vaccine candidates against SARS-CoV-2 in Geneva on January 30, 2020 (31) and identified at least five leading candidate vaccines for SARS-CoV-2 (39). Many countries are engaged in the process of vaccine, but all the studies from various countries are currently in the pre-clinical phase. Only the biggest news related to the development of vaccine has come from Moderna Inc. with its candidate - m RNA 1273 showing signs that it can create an immune response to fend off the Novel Coronavirus. However, data is based on 8 people trial only needs more clinical trials.

Another candidate British Pharmaceutical giant Astrazeneca with University of Oxford produced a vaccine prototype which have also reached clinical trial stage and hoping vaccine candidate for masses.

To conclude the management of rapidly rising cases of Covid-19 has raised alarms in the healthcare facilities all around the globe. In the absence of specific knowledge regarding its mode of transmission animal reservoir source the only alternative is to follow the guidelines of WHO, ICMR and the national government. Further-more, research and development of specific vaccine and drugs against the unbridled infection are the need of the hour.

\section{References}

1. Who. Coronavirus. Available from: https://www.who.int/healthtopics/coronav irus.

2. WHO. Naming the coronavirus disease (COVID-19) and the virus that causes it. Available from: https://www.who.int/emergencies/disease s/novel-coronavirus-2019/technicalguidance/naming-thecoronavirus-disease(covid-2019)-and-the-virus-that-causes-it.

3. (7,14)Chan JF, Yuan S, Kok KH, et al. (January 2020). "A familial cluster of pneumonia associated with the 2019 novel coronavirus indicating person-toperson transmission: a study of a family cluster". Lancet. doi:10.1016/S01406736(20)30154-9

(https://doi.org/10.1916\%2FS0140-

6736\%2820\%2930154-9). PMID 31986261

(https://pubmed.ncbi.nlm.nih.gov/319862 61).

4. Perlman S (January 2020). "Anpther Decade, Another Coronavirus". New England Journal of Medicine. doi:10.1056/NEJMe2001126 (https://doi.org/10.1056\%2FNEJMe2001 
126) PMID 31978944

(https://pubmed.ncbi.nlm.nih.gov/319789 44).

5. WU JT, LeungK, Leung GM (January 2020). "Nowcasting and forecasting the potential domestic and internation spread of the 2019-nCoV outbreak originating in Wuhan, China: a modelling study". Lancet. doi:10.1016/S0140-

6736(20)30260-9

(https://doi.org/10.1016\%2FS0140-

6736\%2820\%2930260-9).

PMID 32014114

(https://pubmed.ncbi.nlm.nih.gov/320141 14).

6. BMJ Best Practice; 2020. Available from : https://bestpractice.bmj.com/topics/en$\mathrm{gb} / 3000165$.

7. Ministry of health and family welfare Government of India Covid-19 India on $10^{\text {th }}$ June 2020,08:00 IST (GMT+5:30)

8. Pranab Chatterzee, Naziagnagi, Anup Agarwal et al, The 2019 Novel Corona Virus disease (COVID-19): A review of current evidence IJMR 151 Feb\&March 2020 PA 147-159

9. Stewart K. Everything you should know about the Coronavirus outbreak. Pharm J. 2020:1 doi:10,1211/P1,2020,20207629

10. Sheahan TP, SIMS CA, Grahan RL, Menachery VD, Gralinski LE. Broadspectrum antiviral GS-5734 inhibits both epidemic and zoonotic corona viruses. Sci Transl Med. 2017;9(396). Doi:10.1126/scitranslmed.aal3653.

11. Callaway E, Cyranoski D, 2020. Available from: https://www.nature.com/articles/d41586020-00180-8.

12. Banerjee A, Kulesar K, Misra V, Frienman M, Mossman K. Bats and Coronaviruses. Viruses.2019;11(1):41.

13. "How COVID-19 Spreads". U.S. Centers for Disease Control and Prevention $(C D C) . \quad 27 \quad$ January 2020. Archived from the original on 28
January $2020 . \quad$ Retrieved 29

January 2020.

14. "Transmission of Novel Coronavirs (2019-nCoV)"

(https://www.cdc.gov/coronavirus/2019-

ncov/about/transmission.html). U.S.

Centers for Disease Control and Prevention (CDC). 27 January 2020.

Archived

(https://web.archive.org/web/2020012815

2653/https://www.cdc.gov/coronavirs/20

19-ncov/about/transmission.html) from the original on 28 January 2020. Retrieved on 29 January 2020.

15. Kupferschmidt $K$ (February 2020). "Study claiming new coronavirus can be transmitted by people without symptoms was

flawed". Science. doi:10.1126/science.ab b1524.

16. Shen K, Yang Y, Wang T, Zhao D, Jiang $\mathrm{Y}$, et al. Diagnosis, treatment, and prevention of 2019 novel coronavirus infection in children: experts' consensus statement. World

Pediatr.2020;doi:10.1007/s12519-02000343-7.

17. Broor S, Krishnan A, Roy DS, et al. Dynamic patterns of circulating seasonal and pandemic $\mathrm{A}(\mathrm{H} 1 \mathrm{~N} 1) \mathrm{pdm} 09$ influenza viruses from 2007-2010 in and around Delhi, India. PLoS One. 2012; 7(1):e29129. doi:10.1371/journal.pone.0029129

18. Chatterjee P, Seth B, Biswas T. Hotspots of H1N1 influenza in India: analysis of reported cases and deaths (20102017). Trop Doct. 2020; 50(2):166- 169. doi: $10.1177 / 0049475519879357$

19. WHO. Clinical management of severe acute respiratory infection when novel coronavirus (2019-nCoV) infection is suspected. Geneva: WHO; 2020. Available from: https://www.who.int/docs/defaultsource/coronaviruse/clinical- 
management-of-novel-cov.pdf, accessed on Feburary 16, 2020.

20. McIntosh K, Kapikian AZ, Turner HC, Hartley JW, Parrott RH, Chanock RM. Seroepidemiologic studies of coronavirus infection in adults and children. Am $J$ Epidemiol. 1970;91(6):585- 592. doi:10.1093/oxfordjournals.aje.a121171

21. Wang D, Hu B, Hu C, et al. Clinical Characteristics of 138 Hospitalized Patients With 2019 Novel CoronavirusInfected Pneumonia in Wuhan, China. JAMA. 2020; 323(11):1061-1069. doi:10.1001/jama.2020.1585

22. Chen N, Zhou M, Dong X, Qu J, Gong F, Han Y, et al. Epidemiological and clinical characteristics of 99 cases of 2019 novel coronavirus pneumonia in Wuhan, China; A descriptive study. Lancet 2020; 395 : 507-13.

23. Haung $C$, Wang Y, Li X, Ren L, Zhao J, $\mathrm{Hu} \mathrm{Y}$, et al. Clinical features of patients infected with 2019 novel coronavirus in Wuhan, China. Lancet 2020; 385: 497506

24. WHO. Q\&A on coronaviruses (COVID19). Available from: https://www.who.int/mews-room/q-adetail/q-a-coronaviruses.

25. Centre for health security. Diagnostic testing for 2019-nCoV January 28, 2020. Johns Hopkins Bloomber School of Public health; 2020, Available from http:/www.centreforhealthsecurity.org/res ources/Covid-19/200130-n CoVdiagnostics-factsheet pdf, accessed on Feb $16^{\text {th }}, 2020$

26. WHO. Laboratory testing for 2019 novel coronavirus (2019-nCoV) in suspected human cases. Geneva: WHO; 2020.

27. WHO Laboratory testing for coronavirus disease (COVID-19) in suspected human cases. Interim guidance 19 March 2020.

28. Corman V, Landt O, Koopmans M, Zambon M, Peiris M. Diagnostic detection for 2019-nCoV by real-time RTPCR: Protocol and primary evaluation. London: Public Health England; 2020.

29. Chang D, Xu H, Rebaza A, Sharma L, Cruz CSD. Protecting health-care workers from subclinical coronavirus infection. Lancet Respir Med 2020; 8 : PE13.

30. Stewart K. Everything you should know about the coronavirus outbreak. Pharm J. 2020;1.doi:10.1211/PJ.2020.20207629.

31. WHO. DRAFT landscape of COVID-19 candidate vaccines, accessed on Feburary 13, 2020.

32. World Health Organisation. WHO Novel Coronavirus R \& D blueprint, Geneva: WHO;2020

33. Figures and images sourced from Wikipedia.

\section{How to cite this article:}

Aradhya Abrol, Surbhi Abrol, Savita Mahajan, Ram Kishan Abrol and Gurpreet Banga 2020. COVID-19: A Perpetuating Challenge to Health Care Personnel. Int.J.Curr.Microbiol.App.Sci. 9(07): 2430-2436. doi: https://doi.org/10.20546/ijcmas.2020.907.285 